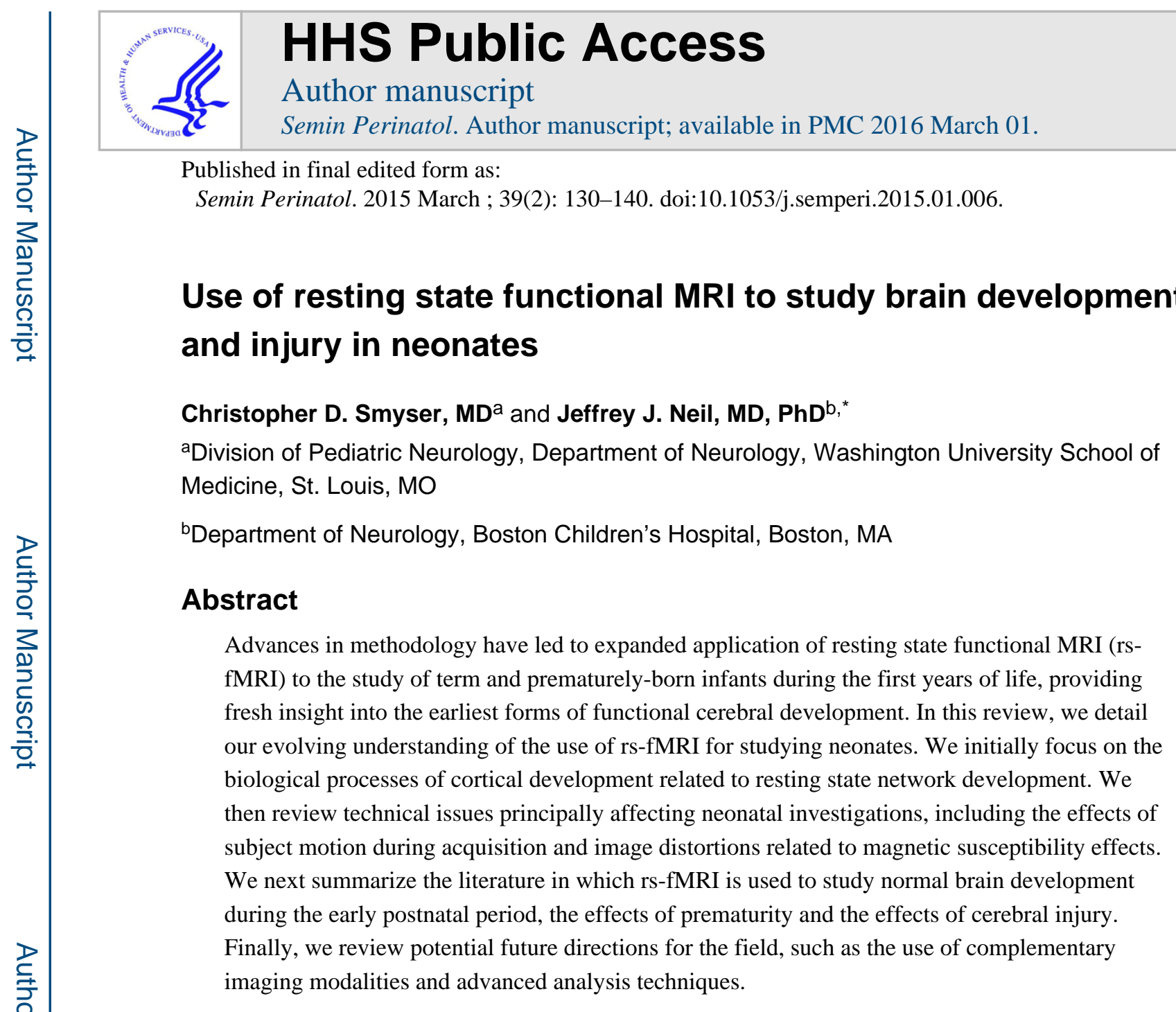

\title{
INTRODUCTION
}

Initially described in Biswal's seminal report, ${ }^{1,2}$ resting state functional magnetic resonance imaging (rsfMRI) investigates the temporal correlations in low frequency $(<0.1 \mathrm{~Hz})$ fluctuations in blood oxygen level dependent (BOLD) signal. These signal fluctuations represent the baseline neuronal activity of the brain in the absence of goal-directed activity and stimulation and are used to identify networks with synchronous, spontaneous neuronal activity, termed resting state networks (RSNs). ${ }^{3,4}$ Investigations, initially in adults and later in older pediatric populations, have consistently identified multiple canonical RSNs located throughout the brain, including the default mode (DMN), dorsal attention (DAN), ventral attention (VAN), frontoparietal control (FPC), cinguloopercular (CO), somatomotor (SMN)

(C) 2015 Published by Elsevier Inc.

*Corresponding author. Jeff Neil, MD, PhD, Neurology, Boston Children's Hospital, 333 Longwood Avenue, LO 450, Boston, MA 02115, phone (617) 355-6388, fax (617) 730-0284, jeffrey.neil@ childrens.harvard.edu.

Publisher's Disclaimer: This is a PDF file of an unedited manuscript that has been accepted for publication. As a service to our customers we are providing this early version of the manuscript. The manuscript will undergo copyediting, typesetting, and review of the resulting proof before it is published in its final citable form. Please note that during the production process errors may be discovered which could affect the content, and all legal disclaimers that apply to the journal pertain.

DISCLOSURE

The authors have nothing to disclose. 
and visual (VIS) networks. ${ }^{5}$ These networks depict the functional topography of the human brain, incorporating cortical and subcortical areas known to be co-activated by tasks involving memory, language, attention, motor activity, sensation and visual performance. Use of the technique has provided novel insight into the neurobiological basis of neurological disease and neurodevelopment, with recent literature implicating networkspecific disruptions in RSN architecture in pediatric disorders such as autism ${ }^{6}$, attention deficit hyperactivity disorder ${ }^{7}$ and Tourette syndrome. ${ }^{8,9}$

Early neuroimaging assessments of cerebral function in neonates were typically limited to task-based investigations defining the anatomic localization of responses to visual, auditory and motor stimuli. ${ }^{10-17}$ Subsequently, by eliminating the need for a subject to perform a task or attend to a stimulus, rs-fMRI afforded investigators a newfound, expanded ability to study the functional cerebral architecture of the developing brain, complementing information available through modalities such as surface-based morphometry, volumetrics and diffusion tensor imaging (DTI). This lead to targeted investigation of whether RSNs, or their precursors, were detectable in term and very preterm (VPT; born $\_30$ weeks gestation) infant populations, including those with cerebral injury. Beginning with the initial description of immature forms of five RSNs in a cohort of VPT infants studied at term equivalent postmenstrual age (PMA) by Fransson and colleagues, ${ }^{18}$ use of the technique to study the earliest forms of functional cerebral development has become increasingly established. The current literature details the presence and patterns of longitudinal development of multiple RSNs located throughout the brain in varied infant populations. ${ }^{18-23}$

rs-fMRI acquisition and analysis methods afford many inherent advantages for studying cerebral function in neonates. Importantly, from an acquisition lasting minutes in duration, robust information regarding global connectional properties can be assessed. In addition, data can be acquired from subjects resting quietly, asleep and even under anesthesia because of the limited requirements for participation. Further, commonly used rs-fMRI acquisition and analysis methods are transferrable across institutions, with limited specific equipment requirements. Analysis techniques for identifying and addressing common sources of colored noise in rs-fMRI data in infants, such as subject motion, are now established. Finally, and perhaps most importantly, similar methods can be readily employed to study diverse patient populations, including subjects with cerebral injury, varied perinatal exposures and complicated medical courses. Cumulatively, these benefits simplify experimental procedures while broadening the nature and scope of hypotheses that can be investigated.

Consequently, the use of rs-fMRI to study infants is an expanding field. Investigations have incorporated progressively younger subjects and diverse neonatal populations of interest.

Recent studies have employed state-of-the-art methodology to account for technical issues commonly problematic in neonates. Advanced analysis techniques, including novel quantitative measures, graph theoretical methods and multivariate pattern analysis, have been successfully implemented. Functional and structural measures have been investigated in tandem, providing an early view of the "neonatal connectome" and highlighting the intricacy of the dynamic relationship between structural and functional development. While 
delivering novel insights into the earliest forms of cerebral connectivity, these studies raise new questions regarding the role of RSNs and their utility as a neuroimaging biomarker and/or diagnostic tool at the individual level. Further, despite these advances, questions remain regarding best practices for data acquisition, analysis and interpretation. In this review, we detail the evolving understanding of the use of rs-fMRI for studying early RSN development in neonates. We initially focus on the key biological processes underlying RSN development, review the technical issues relevant to neonatal investigations, discuss the results from infant investigations reported in the literature, and review potential future directions for the field.

\section{THE STRUCTURAL BASIS OF RESTING STATE NETWORKS}

While the precise connection between fluctuations in BOLD signal and alterations in neural activity has yet to be completely elucidated, a brief review of early brain development, from a biological standpoint, provides a framework from which to consider rs-fMRI data. Early brain development is shaped by genetics, the exigencies of establishing synaptic connections, environmental exposure and experience. ${ }^{24}$ It should be noted that the discussion below refers to some events that occur during the first half of fetal development, but that human infants born earlier than 23 weeks gestation usually do not survive. Thus, rsfMRI studies before 23 weeks are impractical until methods are developed to consistently perform these studies in the fetus. Further, infants born at 23 weeks gestation are typically not sufficiently clinically stable to tolerate an MRI study for several weeks, limiting very early investigations.

Neurogenesis begins within the ventricular zone of the neural tube at 5-6 weeks gestation in humans. As dividing cells differentiate, they migrate to form the preplate, which is present by approximately six weeks gestation. By seven weeks, the preplate has matured into the developing cortical plate. A separate layer, the subplate, is formed beneath the cortical plate shortly thereafter. ${ }^{25}$ The boundaries of the subplate are initially indistinct, but are clear by 12 weeks gestation. The subplate has its greatest extent (for somatosensory and visual areas) from 26-30 weeks gestation ${ }^{26}$ and gradually involutes thereafter, though a limited number of subplate cells may still be present as late as six months after birth.

The subplate is critical to neurodevelopment because it serves as a staging area for afferent axons that initially form transient synapses in this region at 20-23 weeks gestation. These axons subsequently extend to the developing cortical plate and form more permanent connections at 24-32 weeks gestation. ${ }^{27}$ The number and density of synapses increases steadily throughout early brain development, peaking during the first years of life. ${ }^{28}$ It is interesting to consider that spontaneous neural activity during early development plays a central role in establishing and maintaining neural connections. ${ }^{29,30}$ As a result, the spontaneous neural activity described in premature infants may serve a different function than that described in adults and children. While the subplate and cortical plate are clearly distinct entities both anatomically and physiologically, the spatial resolution of a typical rsfMRI study is not sufficient to distinguish them. ${ }^{31}$ Thus, they have been treated as a single entity in rs-fMRI studies published to date. 
The process of cortical maturation outlined above is not spatially uniform. As initially described by Conel, ${ }^{32-37}$ cortical maturation begins in the primary motor and sensory cortices and is followed by other more distal regions. Further, it occurs earliest in areas close to the insula and radiates outward, progressing more slowly in regions more distant from the insula such as cortical association areas. ${ }^{32,35,38,39}$ This differential maturation, described initially on the basis of histological investigation, has also been confirmed in DTI studies. ${ }^{40}$ In addition to considering cortical maturation in terms of local structural maturation, it is also possible to consider maturation of networks and their associated connections on the basis of rs-fMRI studies. As described below, these investigations also largely confirm the histological findings. ${ }^{41}$

\section{TECHNICAL ISSUES RELATED TO STUDIES OF INFANTS}

rs-fMRI studies are technically demanding, and studying neonates offers unique challenges related to both data acquisition and analysis. For example, infants will typically move during data acquisition and, unfortunately, cannot be trained lie still like older children. As a result, infants are sometimes sedated. ${ }^{18,19}$ While RSNs can be detected in sedated subjects, sedation affects results. ${ }^{42-44}$ Thus, we recommend that studies be conducted in non-sedated infants. ${ }^{45}$ Even without sedation, there are likely subtle differences between subjects resting quietly and those at different stages of sleep. ${ }^{46}$ Accurately identifying the arousal state of non-sedated subjects requires simultaneous EEG monitoring, which is not yet commonly performed due to the difficulty of acquisition, particularly in infants.

Motion is a problematic issue in rs-fMRI for all investigated populations, but is particularly prevalent in infants. A priori, one might assume that motion would affect sensitivity for discerning networks uniformly. Unfortunately, this is not the case. While motion increases all correlation values, proximal values are increased more than distal ones. As a result, analysis of data sets with excessive motion will make connections between regions that are physically close seem stronger while making connections that are physically further apart seem relatively weaker (Fig 1). This is particularly a problem when comparing two populations for which one moves more than the other. To complicate matters further, regions in lateral orientations to one another tend to undergo greater increases in correlation values due to motion than those in other orientations. ${ }^{47}$ Thus, motion presents a vexing problem for data analysis and interpretation. Developing approaches by which to mitigate motion effects remains an area of active investigation.

Image distortion caused by static magnetic field inhomogeneity is also a common problem in rs-fMRI and is related to the fast image acquisition methods (typically echo planar imaging) used for these studies. The effects are strongest near air-tissue interfaces such as sinuses and the nasal cavity, often prominently affecting the orbitofrontal region. While these effects are less prevalent in infants as sinuses have not yet completely formed, they still must be addressed. One way to address them is to obtain additional imaging data from each subject which can be used to generate a map of the field distortions caused by susceptibility effects. ${ }^{48,49}$ These field maps can then be used to undo the susceptibilityinduced voxel shifts, thereby creating an undistorted image. An efficient variation of this approach involves obtaining an image set in which the phase encode polarity is reversed. ${ }^{50}$ 
The distortions of the images from the original data set and the one in which phase encode polarity is reversed are essentially opposite (i.e., one image is stretched where the other is compressed and vice versa). Thus, the two image sets can be used to create a single undistorted image set. Note that both of these approaches require an additional image data set on which to create the distortion correction. However, if the rs-fMRI data were collected without the necessary additional image data, it still may be possible to correct the distortions. This is because for each scanner, RF coil and subject type (e.g., an infant), the magnetic susceptibility induced field distortions are consistent. As a result, an average field map derived from a group of subjects imaged with the same system can be applied to those for which no map is available. ${ }^{51}$ Though imperfect, this approach can lead to a significant improvement in image quality (Fig 2).

Data analysis in infants also presents unique challenges, one of which is image registration. The size and cortical folding of the brain vary dramatically during early brain development, most markedly between 24 weeks and term equivalent postmenstrual age. Thus, it is important to use a gestational-age specific target atlas, not only for rs-fMRI studies, but also for studies involving tissue identification/segmentation or comparison of brain structure across groups. Such atlases are freely available from a variety of sources (e.g., www.braindevelopment.org and sumsdb.wustl.edu).

\section{RESTING STATE FUNCTIONAL MRI INVESTIGATIONS IN INFANTS}

Gradually increasing numbers of investigations have applied rs-fMRI to study infants, beginning during the neonatal period and extending through the first two years of life. ${ }^{16,17,19-23,41,52-56}$ These inquiries have included heterogeneous subject groups of varied sizes, investigating both healthy, term-born infants and neonatal clinical populations of interest. Studies have been both cross-sectional and longitudinal, and acquisition and analysis techniques have differed across institutions. Despite these differences in study populations and approaches to assessment of connectivity, consistent patterns have emerged in the results from these inquires. These data, complemented by that available through existing histological and neuroradiological approaches, have provided invaluable information regarding early functional cerebral development and a foundation for expanded investigation applying rs-fMRI.

\section{RSN Development in Infants}

Through use of rs-fMRI, it has become increasingly evident that multiple canonical RSNs incorporating cortical and subcortical gray matter regions and the cerebellum are present during infancy. These include RSNs located in primary motor and sensory cortices (e.g., SMN, VIS, auditory) and those involving association cortices (e.g., DMN, FPC, DAN, VAN). Through investigations of VPT infants (and complimented by information available through fetal fMRI investigations, vide infra), the foundations of these networks are identifiable at least as early 26 weeks PMA. Many of these RSNs, particularly their early forms, consist of strong interhemispheric correlations between homotopic counterparts, with intrahemispheric correlations present but quantifiably weaker. Early thalamocortical connectivity is also evident during this period. ${ }^{19,23,57}$ The described RSN topology is consistent with results obtained in adult and older pediatric populations, though the 
correlation of findings between age groups differs based upon network (Fig 3). These similarities (and differences) have now been consistently identified across multiple reports, ${ }^{18-20,23}$ though the terminology used to describe group differences between infant and adult populations has differed (e.g., 'immature', 'precursor', 'proto').

The rate at which correlations within and between RSNs develop differs by network. ${ }^{19,23,41,58}$ It is assumed that early RSN development is dependent upon effective establishment of structural connectivity. ${ }^{59-61}$ Two recent reports have provided rankings for RSN development in infants which closely reflect known rates of cortical development based upon histological evidence as described above. ${ }^{41,58}$ In these studies, RSNs incorporating primary motor and sensory areas, such as the SMN or VIS, are established by term PMA, with topology and strength reflecting adult-like patterns and correlation values. These RSNs are typically located in cortical regions known to mature early (i.e., areas radiating outward from the insula), demonstrate less variability between subjects ${ }^{62}$ and are potentially less susceptible to pathology. ${ }^{41}$ In contrast, higher-order RSNs such as the DMN and DAN are identifiable in quantifiably weaker or topographically incomplete forms at term. ${ }^{18-20,23}$ These RSNs mature non-linearly over the first several years of life, showing greater increases in size and strength during specific developmental epochs. They are more typically located in association cortices known to mature relatively late and demonstrate greater intersubject variability in spatial and temporal patterns. Relationships between RSNs gradually evolve, with correlation between RSN pairs assuming adult-like patterns during this period. ${ }^{58,63}$ This combination of results suggests RSN development is susceptible during critical developmental periods and/or to disruption of key structural processes.

\section{Clinical Factors Affecting RSN Development During Infancy}

A principal area of interest in the neonatal rs-fMRI literature has been the effects of prematurity on RSN development, driven by the deleterious effects of prematurity on cerebral structure identified using other neuroimaging modalities. ${ }^{64,65}$ Early reports employing conventional RSN mapping demonstrated similar RSN topography and qualitative measures between term and VPT infants scanned at comparable PMA. 18,19,23 However, subsequent use of quantitative measures have demonstrated clear group differences in intrinsic brain activity between these populations (Fig 4). ${ }^{41}$ Specifically, prematurity leads to RSN-specific reductions in network amplitude and dimensionality, a measure which reflects network complexity. The rs-fMRI literature suggests these RSN differences may be indicative of pathology, though the exact etiology remains undetermined. ${ }^{66}$ Importantly, these disruptions persist into early childhood, ${ }^{54}$ adolescence ${ }^{67,68}$ and even early adulthood. ${ }^{69}$ However, their long-term effects on RSN architecture and their role in adverse neurodevelopmental outcomes remains incompletely investigated.

Our evolving understanding of RSN development suggests other key clinical factors and/or environmental exposures may also affect early RSN development, either individually or cumulatively. For example, it has been shown that forms of white matter injury common in infants born prematurely, including intraventricular hemorrhage (IVH) and cystic periventricular leukomalacia (cPVL), affect RSN development in VPT infants in a manner 
dependent upon injury severity and the proximity to the injury site. ${ }^{56,70}$ In addition, RSN-

specific reductions in correlation strength have been identified in prematurely-born infants at term equivalent PMA who have high exposure to stressful and/or painful procedures. ${ }^{71}$

Finally, recent reports suggest key variables such as sex and socioeconomic status may also affect the rate and patterns of RSN development in a network-specific manner. ${ }^{58}$ The impact of these and other clinical variables inherent to the Neonatal Intensive Care Unit environment previously linked to disruption of early cerebral development, including infection, ${ }^{72}$ patent ductus arteriosis ligation ${ }^{73}$ and lung disease ${ }^{74}$, requires continued targeted investigation.

\section{Innovative Analytic Approaches for Infant rs-fMRI Data}

Recently, advanced analytic approaches have been successfully adapted from the adult literature to analyze neonatal rs-fMRI data. These include use of alternative measures of functional connectivity and application of advanced mathematical techniques. Principal among these is use of graph-theoretical analyses, which uses mathematical models to examine pairwise relationships between objects. This methodology can be applied to functional and structural neuroimaging data to characterize network topology and identify "cortical hubs" - regions critical for integration and distribution of information. Recent investigations have applied these network analysis approaches to demonstrate infants possess many of the 'small world' organizational features in network architecture reported in adults, though the location and strength of cortical hubs may differ. ${ }^{55,75} \mathrm{~A}$ second approach to analysis involves measuring covariance. Covariance is a connectivity measure which preserves sensitivity to the magnitude of BOLD signal fluctuations, providing a more sensitive measure than correlation for detection of rs-fMRI abnormalities. ${ }^{76,77}$ Covariance measures within and between RSNs were recently used to define group differences in infant and pediatric investigations. ${ }^{41,56,76}$ Dimensionality estimation is another novel connectivity measure which provides a quantitative index of the complexity of intrinsic brain activity and RSN segregation. ${ }^{78}$ This technique was also recently used to illustrate differences between term and VPT infants. Of note, best practices for applying these mathematical approaches across populations of all ages continue to evolve, with the possibility of novel information afforded by advances in methodology. ${ }^{47}$ Even still, this combination of results emphasizes the importance of extending conventional methods comparing RSN mapping results to include quantitative analyses of rs-fMRI data that increase sensitivity for delineating individual and group differences within and between RSNs.

\section{FUTURE DIRECTIONS}

Several avenues of novel and innovative research employing rs-fMRI in infant populations are being explored. Using currently accepted acquisition and analysis techniques, these investigations center upon providing greater understanding of the dynamic relationship between structural and functional connectivity, exploring the clinical utility of rs-fMRI for predicting neurodevelopmental outcome and examining new methodological approaches and neuroimaging modalities for assessing cerebral functional connectivity. 


\section{Exploration of the Neonatal Connectome}

Though differences exist, anatomical and functional connectivity are interrelated on multiple levels. ${ }^{44}$ Recent studies suggest RSN strength and spatial characteristics at both the local and global level are dependent upon cerebral structural architecture. ${ }^{79-81}$ Investigations combining rs-fMRI measures with those of microstructural architecture, typically assessed via measures of anisotropic water molecule diffusion using DTI, ${ }^{82}$ have attempted to comprehensively define the "human connectome," a detailed map of the neuronal connectional matrix in the human brain. ${ }^{83}$ Smaller-scale studies have recently reported that "connectome-like" organizational properties are also evident in prematurely-born infants. ${ }^{84,85}$ Combining results across modalities provides increased breadth to assessments of cerebral connectivity, delivering more detailed descriptions of the heterogeneous patterns of cerebral development across the brain, including in subjects with cerebral injury and/or abnormality. ${ }^{11,86-90}$ With both methodologies increasingly established, expanded systematic investigation combining techniques across neonatal populations of interest will provide improved comprehension of the evolving interactions between microstructural architecture and emerging functional connections.

\section{Defining the Effects of Clinical Variables on Functional Cerebral Development}

The effects of clinical variables, cerebral injury and subsequent neural plasticity on RSN development continue to be explored. As noted above, it has been demonstrated that cerebral injury (e.g., stroke, IVH, cPVL) powerfully disrupts RSN development in manner dependent upon proximity to the injury site and severity of injury in both pediatric and adult populations. ${ }^{56}$ While this study demonstrates effects local to the injury site, the widespread effects of these disruptions across networks in neonates are less clear. In adults, there is suggestion that injury in specific locations (e.g., medial parietal cortex, anterior insula, superior frontal cortex and temporo-occipital cortex) may produce more potent large-scale effects. ${ }^{91}$ Whether similar global effects occur during infancy remains to be determined. Further, the ability of disrupted RSNs to "recover" either spontaneously or via neuroprotective therapies or intensive training administered following injury during a period when the brain demonstrates a high degree of plasticity remains unknown. ${ }^{30,92}$ These principles shape the interpretation of rs-fMRI investigations in specific infant populations known to be susceptible to cerebral injury and that face recurrent exposure to varied and potentially deleterious environmental stimuli (i.e., the NICU environment). In addition, the effects of clinical variables such as sex and ethnicity on RSN development in neonates remain to be fully explored. ${ }^{62,93,94}$ Further targeted investigation employing rs-fMRI has the potential to define the local and global effects of risk factors in neurodevelopmental outcome and the efficacy of neuroprotective interventions in fostering RSN recovery following injury.

\section{Use of rs-fMRI Results for Prediction of Neurodevelopmental Outcomes}

Significant investigation remains necessary to translate our evolving understanding of early cerebral connectivity to predictive models of developmental performance. Key to this will be prospective, longitudinal investigations correlating neonatal rs-MRI results with childhood neurodevelopmental outcomes. Investigations seeking to establish rs-fMRI as a 
biomarker for brain injury and risk for subsequent neurodevelopmental delay in normal and high-risk (e.g., VPT infants) neonatal populations are ongoing. Early results suggest relationships between specific connectivity and neurodevelopmental performance during the first two years of life, though no longitudinal relationships have been identified using data from the neonatal period to predict subsequent outcome. ${ }^{57}$ Success in these endeavors will likely require use of innovative data analysis strategies such as support vector machine (SVM) multivariate pattern analysis ${ }^{95-100}$ and its extension to SVM regression. ${ }^{101}$ Using this global approach, large data sets, such as rs-fMRI data and outcomes for a population of VPT infants, can be used to "train" the model to identify features most relevant for predicting outcome (Fig 5). This is interesting scientifically because identification of the relevant features provides an indication of which networks are most relevant for neurodevelopmental outcomes. However, this approach also has a more practical application. In theory, it can be used to predict outcome for an individual infant on the basis of his/her rs-fMRI data. (It should be noted that other forms of clinical and/or imaging data can also potentially be incorporated into the model.) This can be helpful for identifying infants at high risk for neurodevelopmental disability who are most likely to benefit from therapy services. It could also potentially be useful for prospective trials of neuroprotective strategies.

\section{Development of Complementary Modalities for Functional Connectivity Assessment}

Development of complementary techniques for mapping early functional cerebral development is ongoing, with results validated against those obtained using concurrent rsfMRI. Principal among these are EEG, ${ }^{102,103}$ near infrared spectroscopy (NIRS) ${ }^{104,105}$ and diffuse optical tomography (DOT). ${ }^{106-108}$ High-density DOT (HD-DOT) is a portable modality which capitalizes upon recent advances in optical imaging to enable continuous, quantitative assessment of cortical RSNs at the bedside. ${ }^{108,109}$ HD-DOT overcomes the challenges pertaining to image quality and signal discrimination faced by many optical imaging systems (i.e., near infrared spectroscopy). Analysis techniques used for rs-fMRI data can also be readily employed in HD-DOT. While there are differences in spatial resolution between the techniques, HD-DOT results in term infants demonstrate strong qualitative and quantitative congruence with those obtained using rs-fMRI. Further development of this technique may enable utilization of rs-fMRI methodology in investigations of neonates unsuitable for transport to the MRI scanner due to technical and/or logistical challenges.

\section{Aspects of rs-fMRI in Neonates Requiring Further Study}

Despite numerous advances in the field, obstacles persist in the rational application and interpretation of rs-fMRI in neonatal populations. Principal among these is our incomplete understanding of the effects of cerebral growth and development on the BOLD signal on which rs-fMRI investigations are based. It has been demonstrated that the hemodynamic response to stimulation changes throughout early development, presumably as a result of dynamic changes in neurovascular coupling and cerebrovascular physiology. ${ }^{11}$ Further, use of age appropriate hemodynamic response function models improves the accuracy of results in task-based fMRI investigations. However, normal limits for various BOLD measures in subjects of differing PMA remain to be firmly established. In addition, cerebral injury, 
common in both infants born prematurely and neonatal clinical populations of interest, may induce significant changes in cerebral blood flow, and subsequently BOLD signal. ${ }^{110}$ This lack of standardization confounds interpretation of BOLD signal correlations, often confusing interpretation of signal magnitude and leading to selection of arbitrary thresholds for analysis in neonates. ${ }^{3,111}$ Further inquiry in this area is critical for maximizing the potential of rs-fMRI investigation in this population.

Best practices for rs-fMRI data acquisition, analysis and interpretation in neonates have become increasingly understood. As has been recently detailed, these complex procedures are critical for mitigating the introduction of colored noise due to non-neuronal signal into rs-fMRI results. ${ }^{112}$ Despite these advances, differences persist across institutions with respect to key variables such as voxel size/slice thickness, use of sedating medications during acquisition and motion correction procedures. Further, while standardized approaches are typically used across all neonatal populations at each institution, it is uncertain whether identical scanner settings and analysis procedures accurately account for the significant differences in brain volume and cortical structure across neonates of differing PMA. In addition, test-retest reliability of results, key to establishment of normative values, has been performed on only a limited basis in this population. ${ }^{79,113}$ Finally, methodological advances increasingly employed in adults, such as use of electroencephalography (EEG) to define subject state during acquisition, are not typically performed in this age group. As these approaches are extrapolated to neonatal populations, ${ }^{114}$ they may provide critical information regarding key variables such as the effects of state change on rs-fMRI results. ${ }^{115}$ The potential for artifactual discrepancies introduced into measured results by these differences in standard procedures must be considered when comparing and interpreting rs-fMRI results across investigations.

Finally, control populations for investigations of prematurely-born infants remain to be definitively identified. In tandem with increasing application of fetal MRI in clinical practice, significant strides have been reported in the application of fMRI to study human fetuses. ${ }^{116-119}$ Targeted investigations in this field have centered upon addressing the numerous and unique technical challenges specific to this population. ${ }^{116,118,120-122}$ With these methods increasingly established, investigators have studied fetuses during the last half of pregnancy. Early results have reported findings in fetuses similar to those reported in neonatal populations scanned at similar postmenstrual age, including primitive forms of many RSNs. ${ }^{117,118}$ Similar to results found in neonatal populations, these RSNs demonstrate interhemispheric correlation between homotopic counterparts and increasing long-range connectivity with advancing age. ${ }^{116,119}$ Modular organization of these networks has also been reported. ${ }^{123}$ However, best practices for comparing fetal and neonatal data acquired and analyzed using differing approaches remain to be determined. In addition, similar to investigations of neonates, acquisition, analysis and interpretation techniques continue to evolve. With continued advances, both populations will continue to provide mutual information regarding the earliest forms of functional connectivity and the antecedents of neurological injury and neurodevelopmental disability. 


\section{CONCLUSIONS}

rs-fMRI provides a novel and valuable mechanism for assessing early functional cerebral development in normal and high-risk infant populations. Advances in rs-fMRI methodology now enable consistent, robust assessment of RSN development in neonatal populations. Recent investigations in term- and prematurely-born infants have demonstrated multiple RSNs are consistently identifiable, with results bearing strong similarity to findings in older pediatric and adult populations. The rate at which these RSNs develop reflects known patterns of cortical development based upon histological investigations, with RSNs demonstrating increasing strength with advancing age. Multiple analysis approaches have recently been developed and employed to identify differences in RSNs between infant populations at the group and individual level. While the foundation for expanded investigation has been established, further exploration of the clinical utility of rs-fMRI in neonates remains necessary. Initial activities should focus upon elucidating the relationship between neonatal RSN development and childhood neurodevelopmental outcomes, efforts necessary to establish this technique as a biomarker for prediction of individual developmental outcomes.

\section{Acknowledgements}

This work was supported by the National Institutes of Health (grant numbers K02 NS089852 and UL1 TR000448), Cerebral Palsy International Research Foundation and The Dana Foundation.

The authors would like to thank Tara Smyser for useful comments on the manuscript.

\section{CITATIONS}

1. Biswal B, Yetkin FZ, Haughton VM, Hyde JS. Functional connectivity in the motor cortex of resting human brain using echo-planar MRI. Magn Reson Med. 1995; 34(4):537-541. [PubMed: 8524021]

2. Lowe MJ, Mock BJ, Sorenson JA. Functional connectivity in single and multislice echoplanar imaging using resting-state fluctuations. Neuroimage. 1998; 7(2):119-132. [PubMed: 9558644]

3. Fox MD, Raichle ME. Spontaneous fluctuations in brain activity observed with functional magnetic resonance imaging. Nat Rev Neurosci. 2007; 8(9):700-711. [PubMed: 17704812]

4. Fox MD, Snyder AZ, Vincent JL, Corbetta M, Van Essen DC, Raichle ME. The human brain is intrinsically organized into dynamic, anticorrelated functional networks. Proc Natl Acad Sci U S A. 2005; 102(27):9673-9678. [PubMed: 15976020]

5. Raichle ME. Two views of brain function. Trends Cogn Sci. 2010; 14(4):180-190. [PubMed: 20206576]

6. Redcay E, Moran JM, Mavros PL, Tager-Flusberg H, Gabrieli JD, Whitfield-Gabrieli S. Intrinsic functional network organization in high-functioning adolescents with autism spectrum disorder. Front Hum Neurosci. 2013; 7:573. [PubMed: 24062673]

7. Posner J, Park C, Wang Z. Connecting the dots: a review of resting connectivity MRI studies in attention-deficit/hyperactivity disorder. Neuropsychol Rev. 2014; 24(1):3-15. [PubMed: 24496902]

8. Church JA, Fair DA, Dosenbach NU, Cohen AL, Miezin FM, Petersen SE, Schlaggar BL. Control networks in paediatric Tourette syndrome show immature and anomalous patterns of functional connectivity. Brain. 2009; 132(Pt 1):225-238. [PubMed: 18952678]

9. Greene DJ, Koller JM, Robichaux-Viehoever A, Bihun EC, Schlaggar BL, Black KJ. Reward enhances tic suppression in children within months of tic disorder onset. Dev Cogn Neurosci. 2014 
10. Arichi T, Gordon-Williams R, Allievi A, Groves AM, Burdet E, Edwards AD. Computercontrolled stimulation for functional magnetic resonance imaging studies of the neonatal olfactory system. Acta Paediatr. 2013; 102(9):868-875. [PubMed: 23789919]

11. Arichi T, Moraux A, Melendez A, Doria V, Groppo M, Merchant N, Combs S, Burdet E, Larkman DJ, Counsell SJ, Beckmann CF, Edwards AD. Somatosensory cortical activation identified by functional MRI in preterm and term infants. Neuroimage. 2010; 49(3):2063-2071. [PubMed: 19854281]

12. Born AP, Miranda MJ, Rostrup E, Toft PB, Peitersen B, Larsson HB, Lou HC. Functional magnetic resonance imaging of the normal and abnormal visual system in early life. Neuropediatrics. 2000; 31(1):24-32. [PubMed: 10774992]

13. Born P, Leth H, Miranda MJ, Rostrup E, Stensgaard A, Peitersen B, Larsson HB, Lou HC. Visual activation in infants and young children studied by functional magnetic resonance imaging. Pediatr Res. 1998; 44(4):578-583. [PubMed: 9773849]

14. Erberich SG, Panigrahy A, Friedlich P, Seri I, Nelson MD, Gilles F. Somatosensory lateralization in the newborn brain. Neuroimage. 2006; 29(1):155-161. [PubMed: 16112875]

15. Heep A, Scheef L, Jankowski J, Born M, Zimmermann N, Sival D, Bos A, Gieseke J, Bartmann P, Schild H, Boecker H. Functional magnetic resonance imaging of the sensorimotor system in preterm infants. Pediatrics. 2009; 123(1):294-300. [PubMed: 19117895]

16. Lee W, Donner EJ, Nossin-Manor R, Whyte HE, Sled JG, Taylor MJ. Visual functional magnetic resonance imaging of preterm infants. Dev Med Child Neurol. 2012; 54(8):724-729. [PubMed: 22715952]

17. Perani D, Saccuman MC, Scifo P, Anwander A, Spada D, Baldoli C, Poloniato A, Lohmann G, Friederici AD. Neural language networks at birth. Proc Natl Acad Sci U S A. 2011; 108(38): 16056-16061. [PubMed: 21896765]

18. Fransson P, Skiold B, Horsch S, Nordell A, Blennow M, Lagercrantz H, Aden U. Resting-state networks in the infant brain. Proc Natl Acad Sci U S A. 2007; 104(39):15531-15536. [PubMed: 17878310]

19. Doria V, Beckmann CF, Arichi T, Merchant N, Groppo M, Turkheimer FE, Counsell SJ, Murgasova M, Aljabar P, Nunes RG, Larkman DJ, Rees G, Edwards AD. Emergence of resting state networks in the preterm human brain. Proc Natl Acad Sci U S A. 2010; 107(46):2001520020. [PubMed: 21041625]

20. Fransson P, Skiold B, Engstrom M, Hallberg B, Mosskin M, Aden U, Lagercrantz H, Blennow M. Spontaneous brain activity in the newborn brain during natural sleep--an fMRI study in infants born at full term. Pediatr Res. 2009; 66(3):301-305. [PubMed: 19531974]

21. Gao W, Zhu H, Giovanello KS, Smith JK, Shen D, Gilmore JH, Lin W. Evidence on the emergence of the brain's default network from 2-week-old to 2-year-old healthy pediatric subjects. Proc Natl Acad Sci U S A. 2009; 106(16):6790-6795. [PubMed: 19351894]

22. Lin W, Zhu Q, Gao W, Chen Y, Toh CH, Styner M, Gerig G, Smith JK, Biswal B, Gilmore JH. Functional connectivity MR imaging reveals cortical functional connectivity in the developing brain. AJNR Am J Neuroradiol. 2008; 29(10):1883-1889. [PubMed: 18784212]

23. Smyser CD, Inder TE, Shimony JS, Hill JE, Degnan AJ, Snyder AZ, Neil JJ. Longitudinal analysis of neural network development in preterm infants. Cereb Cortex. 2010; 20(12):2852-2862. [PubMed: 20237243]

24. Geschwind DH, Rakic P. Cortical evolution: judge the brain by its cover. Neuron. 2013; 80(3): 633-647. [PubMed: 24183016]

25. Bystron I, Blakemore C, Rakic P. Development of the human cerebral cortex: Boulder Committee revisited. Nat Rev Neurosci. 2008; 9(2):110-122. [PubMed: 18209730]

26. Kostovic I, Rakic P. Developmental history of the transient subplate zone in the visual and somatosensory cortex of the macaque monkey and human brain. J Comp Neurol. 1990; 297(3): 441-470. [PubMed: 2398142]

27. Kostovic I, Jovanov-Milosevic N. The development of cerebral connections during the first 20-45 weeks' gestation. Semin Fetal Neonatal Med. 2006; 11(6):415-422. [PubMed: 16962836]

28. Huttenlocher PR. Synapse elimination and plasticity in developing human cerebral cortex. Am J Ment Defic. 1984; 88(5):488-496. [PubMed: 6731486] 
29. Kerschensteiner D. Spontaneous Network Activity and Synaptic Development. Neuroscientist. 2013; 20(3):272-290. [PubMed: 24280071]

30. Penn AA, Shatz CJ. Brain waves and brain wiring: the role of endogenous and sensory-driven neural activity in development. Pediatr Res. 1999; 45(4 Pt 1):447-458. [PubMed: 10203134]

31. Kostovic I, Vasung L. Insights from in vitro fetal magnetic resonance imaging of cerebral development. Semin Perinatol. 2009; 33(4):220-233. [PubMed: 19631083]

32. Conel, JL. The Cortex of the Newborn. Cambridge, MA: Harvard University Press; 1939.

33. Luskin MB, Shatz CJ. Neurogenesis of the cat's primary visual cortex. J Comp Neurol. 1985; 242(4):611-631. [PubMed: 4086673]

34. Rakic P. Prenatal genesis of connections subserving ocular dominance in the rhesus monkey. Nature. 1976; 261(5560):467-471. [PubMed: 819835]

35. Sidman, RL.; Rakic, P. Development of the human central nervous system. In: Haymaker, W.; Adams, RD., editors. Histology and Histopathology of the Nervous System. Springfield: C.C. Thomas; 1982. p. 3-145.

36. Smart IH. Three dimensional growth of the mouse isocortex. J Anat. 1983; 137(Pt 4):683-694. [PubMed: 6668246]

37. Smart IH, Dehay C, Giroud P, Berland M, Kennedy H. Unique morphological features of the proliferative zones and postmitotic compartments of the neural epithelium giving rise to striate and extrastriate cortex in the monkey. Cereb Cortex. 2002; 12(1):37-53. [PubMed: 11734531]

38. Ball G, Srinivasan L, Aljabar P, Counsell SJ, Durighel G, Hajnal JV, Rutherford MA, Edwards AD. Development of cortical microstructure in the preterm human brain. Proc Natl Acad Sci U S A. 2013; 110(23):9541-9546. [PubMed: 23696665]

39. Travis K, Ford K, Jacobs B. Regional dendritic variation in neonatal human cortex: a quantitative Golgi study. Dev Neurosci. 2005; 27(5):277-287. [PubMed: 16137985]

40. Kroenke CD, Van Essen DC, Inder TE, Rees S, Bretthorst GL, Neil JJ. Microstructural changes of the baboon cerebral cortex during gestational development reflected in magnetic resonance imaging diffusion anisotropy. J Neurosci. 2007; 27(46):12506-12515. [PubMed: 18003829]

41. Smyser CD, Snyder AZ, Shimony JS, Mitra A, Inder TE, Neil JJ. Resting-State Network Complexity and Magnitude Are Reduced in Prematurely Born Infants. Cereb Cortex. 2014

42. Greicius MD, Kiviniemi V, Tervonen O, Vainionpaa V, Alahuhta S, Reiss AL, Menon V. Persistent default-mode network connectivity during light sedation. Hum Brain Mapp. 2008; 29(7):839-847. [PubMed: 18219620]

43. Stamatakis EA, Adapa RM, Absalom AR, Menon DK. Changes in resting neural connectivity during propofol sedation. PLoS One. 2010; 5(12):e14224. [PubMed: 21151992]

44. Vincent JL, Patel GH, Fox MD, Snyder AZ, Baker JT, Van Essen DC, Zempel JM, Snyder LH, Corbetta M, Raichle ME. Intrinsic functional architecture in the anaesthetized monkey brain. Nature. 2007; 447(7140):83-86. [PubMed: 17476267]

45. Mathur AM, Neil JJ, McKinstry RC, Inder TE. Transport, monitoring, and successful brain MR imaging in unsedated neonates. Pediatr Radiol. 2008; 38(3):260-264. [PubMed: 18175110]

46. Duyn J. Spontaneous fMRI activity during resting wakefulness and sleep. Prog Brain Res. 2011; 193:295-305. [PubMed: 21854970]

47. Power JD, Schlaggar BL, Petersen SE. Recent progress and outstanding issues in motion correction in resting state fMRI. Neuroimage. 2014

48. Cusack R, Brett M, Osswald K. An evaluation of the use of magnetic field maps to undistort echoplanar images. Neuroimage. 2003; 18(1):127-142. [PubMed: 12507450]

49. Jezzard P, Balaban RS. Correction for geometric distortion in echo planar images from B0 field variations. Magn Reson Med. 1995; 34(1):65-73. [PubMed: 7674900]

50. Holland D, Kuperman JM, Dale AM. Efficient correction of inhomogeneous static magnetic fieldinduced distortion in Echo Planar Imaging. Neuroimage. 2010; 50(1):175-183. [PubMed: 19944768]

51. Gholipour A, Kehtarnavaz N, Gopinath K, Briggs R, Panahi I. Average field map image template for Echo-Planar image analysis. Conf Proc IEEE Eng Med Biol Soc. 2008; 2008:94-97. [PubMed: 19162602] 
52. Alcauter S, Lin W, Keith Smith J, Gilmore JH, Gao W. Consistent Anterior-Posterior Segregation of the Insula During the First 2 Years of Life. Cereb Cortex. 2013

53. Damaraju E, Caprihan A, Lowe JR, Allen EA, Calhoun VD, Phillips JP. Functional connectivity in the developing brain: a longitudinal study from 4 to 9 months of age. Neuroimage. 2014; 84:169180. [PubMed: 23994454]

54. Damaraju E, Phillips JR, Lowe JR, Ohls R, Calhoun VD, Caprihan A. Resting-state functional connectivity differences in premature children. Front Syst Neurosci. 2010; 4

55. Fransson $\mathrm{P}$, Aden U, Blennow M, Lagercrantz $\mathrm{H}$. The functional architecture of the infant brain as revealed by resting-state fMRI. Cereb Cortex. 2011; 21(1):145-154. [PubMed: 20421249]

56. Smyser CD, Snyder AZ, Shimony JS, Blazey TM, Inder TE, Neil JJ. Effects of white matter injury on resting state fMRI measures in prematurely born infants. PLoS One. 2013; 8(7):e68098. [PubMed: 23874510]

57. Alcauter S, Lin W, Smith JK, Short SJ, Goldman BD, Reznick JS, Gilmore JH, Gao W. Development of thalamocortical connectivity during infancy and its cognitive correlations. J Neurosci. 2014; 34(27):9067-9075. [PubMed: 24990927]

58. Gao W, Alcauter S, Elton A, Hernandez-Castillo CR, Smith JK, Ramirez J, Lin W. Functional Network Development During the First Year: Relative Sequence and Socioeconomic Correlations. Cereb Cortex. 2014

59. Mrzljak L, Uylings HB, Kostovic I, van Eden CG. Prenatal development of neurons in the human prefrontal cortex. II. A quantitative Golgi study. J Comp Neurol. 1992; 316(4):485-496. [PubMed: 1577996]

60. Petanjek Z, Judas M, Kostovic I, Uylings HB. Lifespan alterations of basal dendritic trees of pyramidal neurons in the human prefrontal cortex: a layer-specific pattern. Cereb Cortex. 2008; 18(4):915-929. [PubMed: 17652464]

61. Petanjek Z, Judas M, Simic G, Rasin MR, Uylings HB, Rakic P, Kostovic I. Extraordinary neoteny of synaptic spines in the human prefrontal cortex. Proc Natl Acad Sci U S A. 2011; 108(32): 13281-13286. [PubMed: 21788513]

62. Gao W, Elton A, Zhu H, Alcauter S, Smith JK, Gilmore JH, Lin W. Intersubject variability of and genetic effects on the brain's functional connectivity during infancy. J Neurosci. 2014; 34(34): 11288-11296. [PubMed: 25143609]

63. Gao W, Gilmore JH, Alcauter S, Lin W. The dynamic reorganization of the default-mode network during a visual classification task. Front Syst Neurosci. 2013; 7:34. [PubMed: 23898240]

64. Ball G, Aljabar P, Zebari S, Tusor N, Arichi T, Merchant N, Robinson EC, Ogundipe E, Rueckert D, Edwards AD, Counsell SJ. Rich-club organization of the newborn human brain. Proc Natl Acad Sci U S A. 2014; 111(20):7456-7461. [PubMed: 24799693]

65. Inder T, Neil J, Yoder B, Rees S. Patterns of cerebral injury in a primate model of preterm birth and neonatal intensive care. J Child Neurol. 2005; 20(12):965-967. [PubMed: 16417843]

66. Fox MD, Greicius M. Clinical applications of resting state functional connectivity. Front Syst Neurosci. 2010; 4:19. [PubMed: 20592951]

67. Constable RT, Vohr BR, Scheinost D, Benjamin JR, Fulbright RK, Lacadie C, Schneider KC, Katz $\mathrm{KH}$, Zhang H, Papademetris X, Ment LR. A left cerebellar pathway mediates language in prematurely-born young adults. Neuroimage. 2013; 64:371-378. [PubMed: 22982585]

68. Myers EH, Hampson M, Vohr B, Lacadie C, Frost SJ, Pugh KR, Katz KH, Schneider KC, Makuch $\mathrm{RW}$, Constable RT, Ment LR. Functional connectivity to a right hemisphere language center in prematurely born adolescents. Neuroimage. 2010; 51(4):1445-1452. [PubMed: 20347043]

69. White TP, Symington I, Castellanos NP, Brittain PJ, Froudist Walsh S, Nam KW, Sato JR, Allin MP, Shergill SS, Murray RM, Williams SC, Nosarti C. Dysconnectivity of neurocognitive networks at rest in very-preterm born adults. Neuroimage Clin. 2014; 4:352-365. [PubMed: 24567907]

70. Arichi T, Counsell SJ, Allievi AG, Chew AT, Martinez-Biarge M, Mondi V, Tusor N, Merchant N, Burdet E, Cowan FM, Edwards AD. The effects of hemorrhagic parenchymal infarction on the establishment of sensori-motor structural and functional connectivity in early infancy. Neuroradiology. 2014; 56(11):985-994. [PubMed: 25119253] 
71. Smith GC, Gutovich J, Smyser C, Pineda R, Newnham C, Tjoeng TH, Vavasseur C, Wallendorf $\mathrm{M}$, Neil J, Inder T. Neonatal intensive care unit stress is associated with brain development in preterm infants. Ann Neurol. 2011; 70(4):541-549. [PubMed: 21976396]

72. Chau V, Brant R, Poskitt KJ, Tam EW, Synnes A, Miller SP. Postnatal infection is associated with widespread abnormalities of brain development in premature newborns. Pediatr Res. 2012; 71(3): 274-279. [PubMed: 22278180]

73. Padilla N, Alexandrou G, Blennow M, Lagercrantz H, Aden U. Brain Growth Gains and Losses in Extremely Preterm Infants at Term. Cereb Cortex. 2014

74. Ball G, Counsell SJ, Anjari M, Merchant N, Arichi T, Doria V, Rutherford MA, Edwards AD, Rueckert D, Boardman JP. An optimised tract-based spatial statistics protocol for neonates: applications to prematurity and chronic lung disease. Neuroimage. 2010; 53(1):94-102. [PubMed: 20510375]

75. Gao W, Gilmore JH, Giovanello KS, Smith JK, Shen D, Zhu H, Lin W. Temporal and spatial evolution of brain network topology during the first two years of life. PLoS One. 2011; 6(9):e25278. [PubMed: 21966479]

76. Pizoli CE, Shah MN, Snyder AZ, Shimony JS, Limbrick DD, Raichle ME, Schlaggar BL, Smyth MD. Resting-state activity in development and maintenance of normal brain function. Proc Natl Acad Sci U S A. 2011; 108(28):11638-11643. [PubMed: 21709227]

77. Varoquaux G, Baronnet F, Kleinschmidt A, Fillard P, Thirion B. Detection of brain functionalconnectivity difference in post-stroke patients using group-level covariance modeling. Med Image Comput Comput Assist Interv. 2010; 13(Pt 1):200-208. [PubMed: 20879232]

78. Sporns O. Network attributes for segregation and integration in the human brain. Curr Opin Neurobiol. 2013; 23(2):162-171. [PubMed: 23294553]

79. Honey CJ, Sporns O, Cammoun L, Gigandet X, Thiran JP, Meuli R, Hagmann P. Predicting human resting-state functional connectivity from structural connectivity. Proc Natl Acad Sci U S A. 2009; 106(6):2035-2040. [PubMed: 19188601]

80. Koch MA, Norris DG, Hund-Georgiadis M. An investigation of functional and anatomical connectivity using magnetic resonance imaging. Neuroimage. 2002; 16(1):241-250. [PubMed: 11969331]

81. Shatz CJ. Emergence of order in visual system development. Proc Natl Acad Sci U S A. 1996; 93(2):602-608. [PubMed: 8570602]

82. Neil JJ, Miller JP, Mukherjee P, Huppi PS. Diffusion Tensor Imaging of Normal and Injured Developing Human Brain. NMR Biomed. 2002; 15:543-552. [PubMed: 12489100]

83. Sporns O, Tononi G, Kotter R. The human connectome: A structural description of the human brain. PLoS Comput Biol. 2005; 1(4):e42. [PubMed: 16201007]

84. Brown CJ, Miller SP, Booth BG, Andrews S, Chau V, Poskitt KJ, Hamarneh G. Structural network analysis of brain development in young preterm neonates. Neuroimage. 2014; 101:667-680. [PubMed: 25076107]

85. van den Heuvel MP, Kersbergen KJ, de Reus MA, Keunen K, Kahn RS, Groenendaal F, de Vries LS, Benders MJ. The Neonatal Connectome During Preterm Brain Development. Cereb Cortex. 2014

86. Greicius MD, Supekar K, Menon V, Dougherty RF. Resting-state functional connectivity reflects structural connectivity in the default mode network. Cereb Cortex. 2009; 19(1):72-78. [PubMed: 18403396]

87. Johnston JM, Vaishnavi SN, Smyth MD, Zhang D, He BJ, Zempel JM, Shimony JS, Snyder AZ, Raichle ME. Loss of resting interhemispheric functional connectivity after complete section of the corpus callosum. J Neurosci. 2008; 28(25):6453-6458. [PubMed: 18562616]

88. Uddin LQ, Mooshagian E, Zaidel E, Scheres A, Margulies DS, Kelly AM, Shehzad Z, Adelstein JS, Castellanos FX, Biswal BB, Milham MP. Residual functional connectivity in the split-brain revealed with resting-state functional MRI. Neuroreport. 2008; 19(7):703-709. [PubMed: 18418243]

89. van den Heuvel M, Mandl R, Luigjes J, Hulshoff Pol H. Microstructural organization of the cingulum tract and the level of default mode functional connectivity. J Neurosci. 2008; 28(43): 10844-10851. [PubMed: 18945892] 
90. Vasung L, Fischi-Gomez E, Huppi PS. Multimodality evaluation of the pediatric brain: DTI and its competitors. Pediatr Radiol. 2013; 43(1):60-68. [PubMed: 23288478]

91. Power JD, Schlaggar BL, Lessov-Schlaggar CN, Petersen SE. Evidence for hubs in human functional brain networks. Neuron. 2013; 79(4):798-813. [PubMed: 23972601]

92. Lewis CM, Baldassarre A, Committeri G, Romani GL, Corbetta M. Learning sculpts the spontaneous activity of the resting human brain. Proc Natl Acad Sci U S A. 2009; 106(41):1755817563. [PubMed: 19805061]

93. Ment LR, Constable RT. Injury and recovery in the developing brain: evidence from functional MRI studies of prematurely born children. Nat Clin Pract Neurol. 2007; 3(10):558-571. [PubMed: 17914344]

94. Weissman-Fogel I, Moayedi M, Taylor KS, Pope G, Davis KD. Cognitive and default-mode resting state networks: do male and female brains "rest" differently? Hum Brain Mapp. 2010; 31(11):1713-1726. [PubMed: 20725910]

95. Ben-Hur A, Ong CS, Sonnenburg S, Scholkopf B, Ratsch G. Support vector machines and kernels for computational biology. PLoS Comput Biol. 2008; 4(10):e1000173. [PubMed: 18974822]

96. Dosenbach NU, Nardos B, Cohen AL, Fair DA, Power JD, Church JA, Nelson SM, Wig GS, Vogel AC, Lessov-Schlaggar CN, Barnes KA, Dubis JW, Feczko E, Coalson RS, Pruett JR Jr, Barch DM, Petersen SE, Schlaggar BL. Prediction of individual brain maturity using fMRI. Science. 2010; 329(5997):1358-1361. [PubMed: 20829489]

97. Ecker C, Rocha-Rego V, Johnston P, Mourao-Miranda J, Marquand A, Daly EM, Brammer MJ, Murphy C, Murphy DG. Investigating the predictive value of whole-brain structural MR scans in autism: a pattern classification approach. Neuroimage. 2010; 49(1):44-56. [PubMed: 19683584]

98. Erus G, Battapady H, Satterthwaite TD, Hakonarson H, Gur RE, Davatzikos C, Gur RC. Imaging Patterns of Brain Development and their Relationship to Cognition. Cereb Cortex. 2014

99. Magnin B, Mesrob L, Kinkingnehun S, Pelegrini-Issac M, Colliot O, Sarazin M, Dubois B, Lehericy S, Benali H. Support vector machine-based classification of Alzheimer's disease from whole-brain anatomical MRI. Neuroradiology. 2009; 51(2):73-83. [PubMed: 18846369]

100. Pereira F, Mitchell T, Botvinick M. Machine learning classifiers and fMRI: a tutorial overview. Neuroimage. 2009; 45(1 Suppl):S199-S209. [PubMed: 19070668]

101. Smola A, Scholkpf B. A tutorial on support vector regression. Statistics and Computing. 2004; 14(3):199-222.

102. Fransson P, Metsaranta M, Blennow M, Aden U, Lagercrantz H, Vanhatalo S. Early development of spatial patterns of power-law frequency scaling in FMRI resting-state and EEG data in the newborn brain. Cereb Cortex. 2013; 23(3):638-646. [PubMed: 22402348]

103. Omidvarnia A, Fransson P, Metsaranta M, Vanhatalo S. Functional bimodality in the brain networks of preterm and term human newborns. Cereb Cortex. 2014; 24(10):2657-2668. [PubMed: 23650289]

104. Homae F, Watanabe H, Nakano T, Taga G. Large-scale brain networks underlying language acquisition in early infancy. Front Psychol. 2011; 2:93. [PubMed: 21687461]

105. Roche-Labarbe N, Fenoglio A, Aggarwal A, Dehaes M, Carp SA, Franceschini MA, Grant PE. Near-infrared spectroscopy assessment of cerebral oxygen metabolism in the developing premature brain. J Cereb Blood Flow Metab. 2012; 32(3):481-488. [PubMed: 22027937]

106. Fuchino Y, Naoi N, Shibata M, Niwa F, Kawai M, Konishi Y, Okanoya K, Myowa-Yamakoshi M. Effects of preterm birth on intrinsic fluctuations in neonatal cerebral activity examined using optical imaging. PLoS One. 2013; 8(6):e67432. [PubMed: 23840698]

107. Liao SM, Ferradal SL, White BR, Gregg N, Inder TE, Culver JP. High-density diffuse optical tomography of term infant visual cortex in the nursery. J Biomed Opt. 2012; 17(8):081414. [PubMed: 23224175]

108. White BR, Liao SM, Ferradal SL, Inder TE, Culver JP. Bedside optical imaging of occipital resting-state functional connectivity in neonates. Neuroimage. 2012; 59(3):2529-2538. [PubMed: 21925609]

109. Eggebrecht AT, Ferradal SL, Robichaux-Viehoever A, Hassanpour MS, Dehghani H, Snyder AZ, Hershey T, Culver JP. Mapping distributed brain function and networks with diffuse optical tomography. Nat Photonics. 2014; 8(6):448-454. [PubMed: 25083161] 
110. Seghier ML, Huppi PS. The role of functional magnetic resonance imaging in the study of brain development, injury, and recovery in the newborn. Semin Perinatol. 2010; 34(1):79-86. [PubMed: 20109975]

111. Ment LR, Hirtz D, Huppi PS. Imaging biomarkers of outcome in the developing preterm brain. Lancet Neurol. 2009; 8(11):1042-1055. [PubMed: 19800293]

112. Van Dijk KR, Hedden T, Venkataraman A, Evans KC, Lazar SW, Buckner RL. Intrinsic functional connectivity as a tool for human connectomics: theory, properties, and optimization. J Neurophysiol. 2010; 103(1):297-321. [PubMed: 19889849]

113. Uddin LQ, Supekar K, Menon V. Typical and atypical development of functional human brain networks: insights from resting-state FMRI. Front Syst Neurosci. 2010; 4:21. [PubMed: 20577585]

114. Vanhatalo S, Alnajjar A, Nguyen VT, Colditz P, Fransson P. Safety of EEG-fMRI recordings in newborn infants at 3T: a study using a baby-size phantom. Clin Neurophysiol. 2014; 125(5):941946. [PubMed: 24252394]

115. Birn RM. The role of physiological noise in resting-state functional connectivity. Neuroimage. 2012; 62(2):864-870. [PubMed: 22245341]

116. Jakab A, Schwartz E, Kasprian G, Gruber GM, Prayer D, Schopf V, Langs G. Fetal functional imaging portrays heterogeneous development of emerging human brain networks. Front Hum Neurosci. 2014; 8:852. [PubMed: 25374531]

117. Schopf V, Kasprian G, Brugger PC, Prayer D. Watching the fetal brain at 'rest'. Int J Dev Neurosci. 2012; 30(1):11-17. [PubMed: 22044604]

118. Thomason ME, Dassanayake MT, Shen S, Katkuri Y, Alexis M, Anderson AL, Yeo L, Mody S, Hernandez-Andrade E, Hassan SS, Studholme C, Jeong JW, Romero R. Cross-hemispheric functional connectivity in the human fetal brain. Sci Transl Med. 2013; 5(173):173ra124.

119. Thomason ME, Grove LE, Lozon TA Jr, Vila AM, Ye Y, Nye MJ, Manning JH, Pappas A, Hernandez-Andrade E, Yeo L, Mody S, Berman S, Hassan SS, Romero R. Age-related increases in long-range connectivity in fetal functional neural connectivity networks in utero. Dev Cogn Neurosci. 2014

120. Fulford J, Vadeyar SH, Dodampahala SH, Ong S, Moore RJ, Baker PN, James DK, Gowland P. Fetal brain activity and hemodynamic response to a vibroacoustic stimulus. Hum Brain Mapp. 2004; 22(2):116-121. [PubMed: 15108299]

121. Rutherford M, Jiang S, Allsop J, Perkins L, Srinivasan L, Hayat T, Kumar S, Hajnal J. MR imaging methods for assessing fetal brain development. Dev Neurobiol. 2008; 68(6):700-711. [PubMed: 18383541]

122. Seshamani S, Cheng X, Fogtmann M, Thomason ME, Studholme C. A method for handling intensity inhomogenieties in fMRI sequences of moving anatomy of the early developing brain. Med Image Anal. 2014; 18(2):285-300. [PubMed: 24317121]

123. Thomason ME, Brown JA, Dassanayake MT, Shastri R, Marusak HA, Hernandez-Andrade E, Yeo L, Mody S, Berman S, Hassan SS, Romero R. Intrinsic functional brain architecture derived from graph theoretical analysis in the human fetus. PLoS One. 2014; 9(5):e94423. [PubMed: 24788455] 


\section{Motion \\ Motion} uncorrected corrected

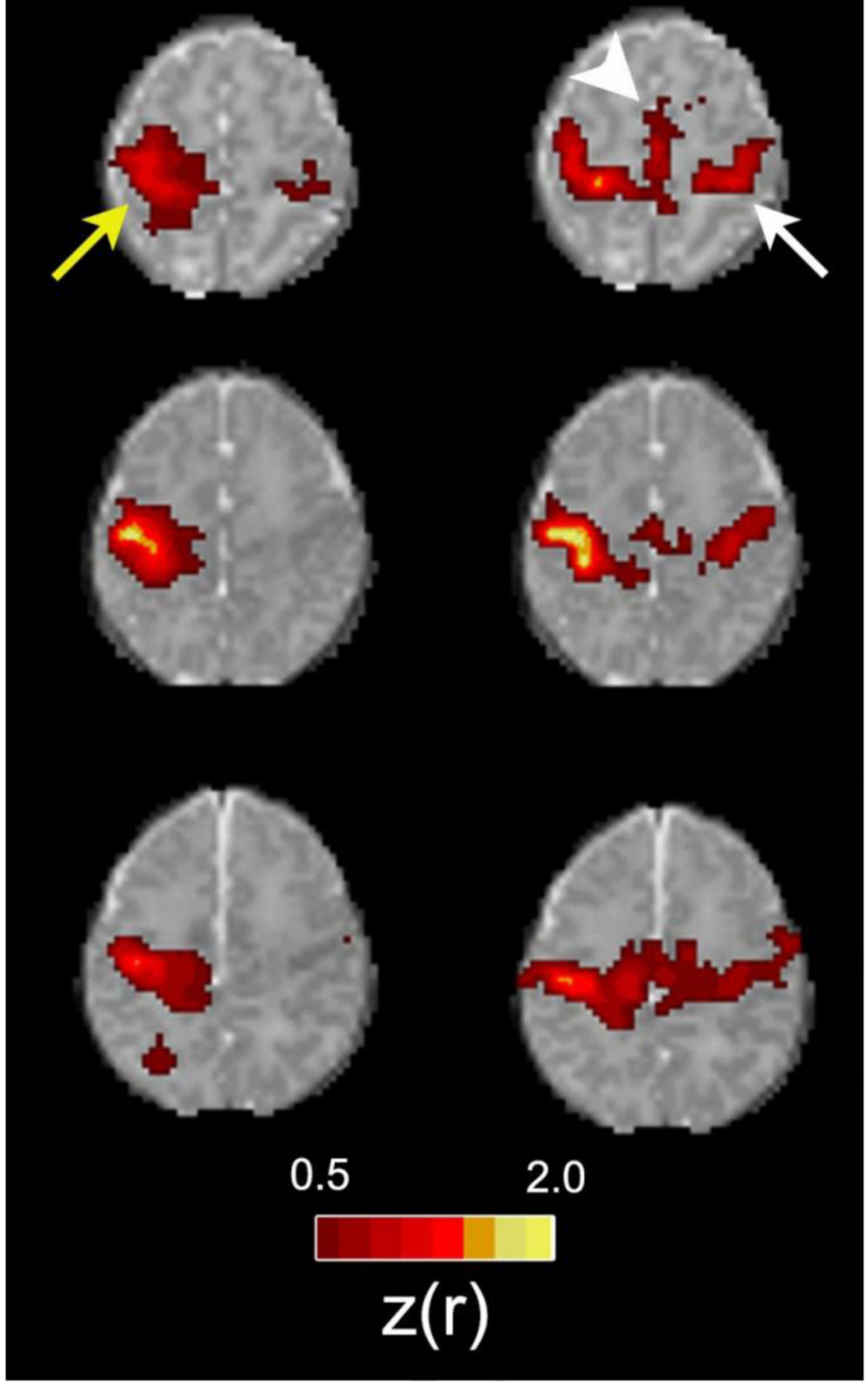

Figure 1. Improvements in rs-fMRI results using rigorous motion correction procedures Each row shows rs-fMRI correlation maps illustrating the motor network for one of three representative healthy, term control infants. The left column shows data derived using all frames acquired during the course of all single scanning session. The right column shows data derived only from frames remaining following rigorous frame censoring procedures. For motion correction, frames were excluded if the volume-to-volume head displacement was $\geq 0.25 \mathrm{~mm}$ or the root mean squared BOLD signal intensity change (DVARS) was $\geq$ $0.3 \%$. Images depict Fisher z-transformed correlation coefficients obtained using a left 
motor cortex seed $(\mathrm{z}(\mathrm{r})$; color threshold value $=0.5)$. Identical slices are shown in both columns for each subject. Note the larger local area of correlation near the seed in the uncorrected data (yellow arrow). Note also that longer range connections to the contralateral motor area (white arrow) and supplemental motor area (white arrowhead) are not detected in the uncorrected data. 


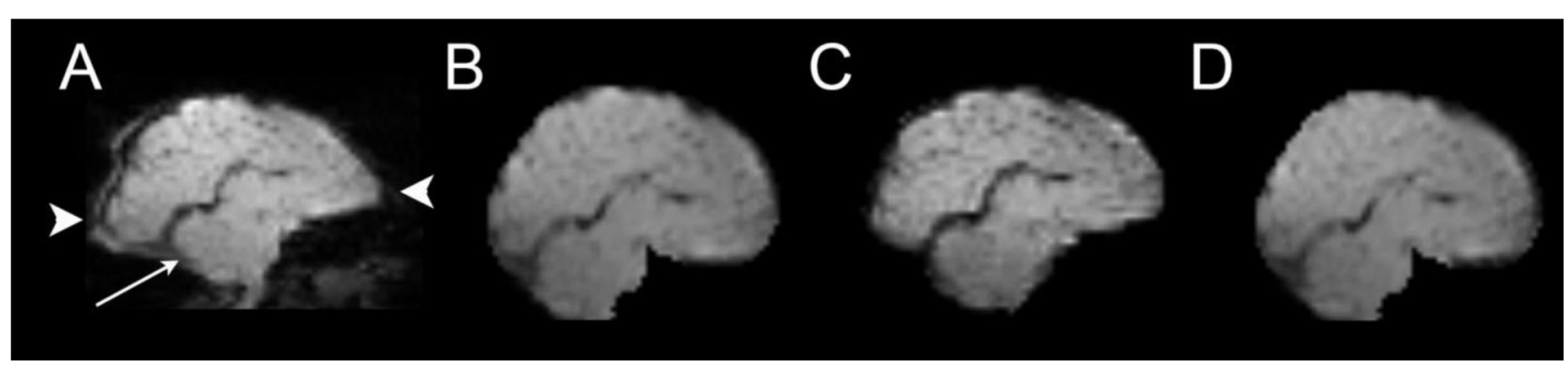

Figure 2. Multiple methods for correcting BOLD distortions due to magnetic field inhomogeneity

A parasaggital image obtained using echo-planar image acquisition. The cerebellum is indicated with an arrow. Image (A) is uncorrected and shows distortions due to magnetic field inhomogeneity caused by magnetic susceptibility effects. Note the stretching of the occipital and frontal lobes (arrowheads). The other images show the results of correction using (B) a self field map (C) top-down distortion correction, and (D) a mean field map. Note the similarity of improvement across all correction approaches. 


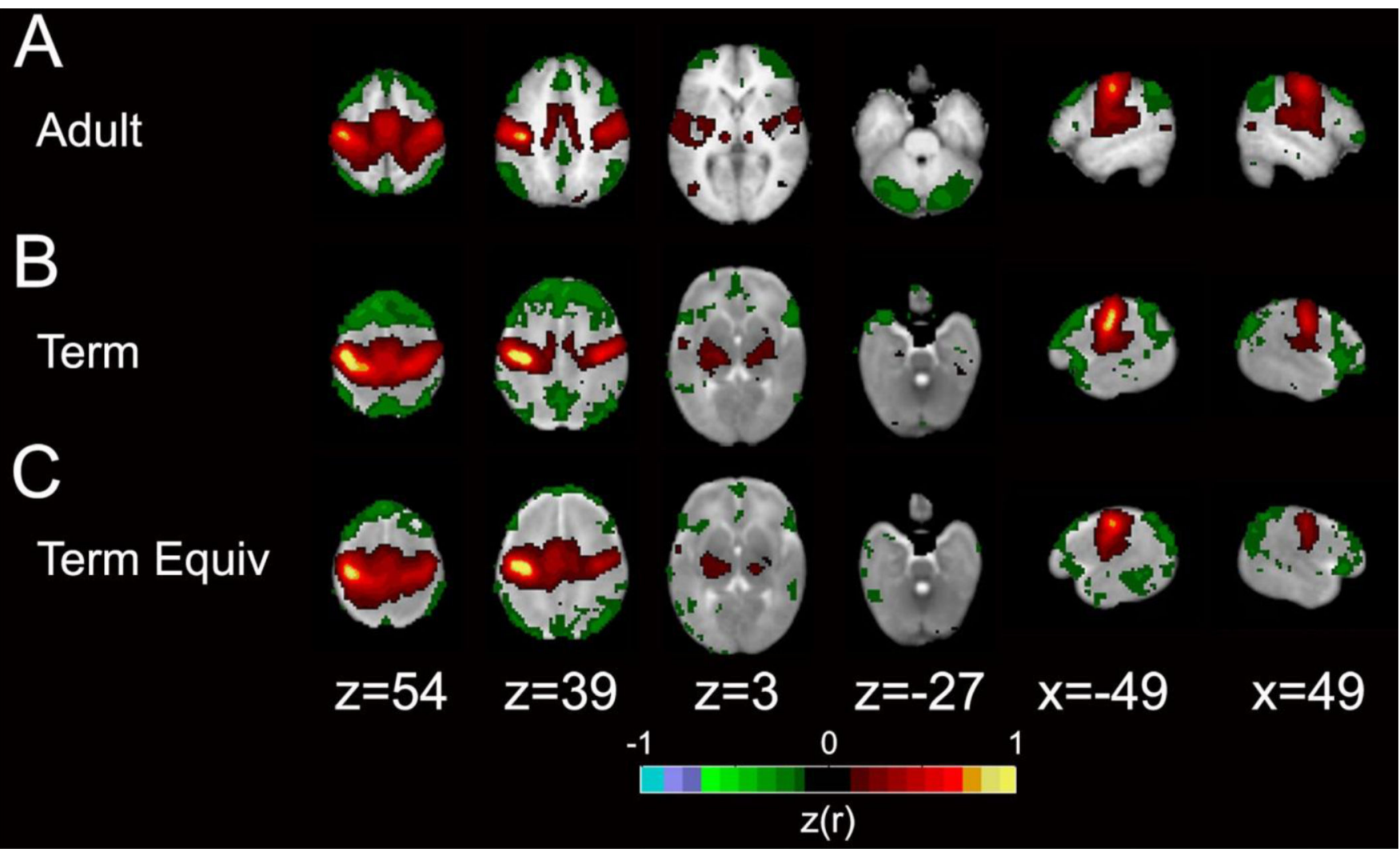

Figure 3. Motor network in adult, term and term equivalent subjects

Group mean rs-fcMRI correlation maps illustrating the motor network. The color scale is the Fisher $z$-transformed correlation coefficients $(z(r)$; color threshold value $=0.12$ ) obtained using a left motor cortex seed overlaid on population-specific, atlas T2-weighted images. Positive correlations are red and yellow, negative correlations are green. The images depict data from (A) an adult, (B) a term control infant and (C) a preterm infant at term equivalent postmenstrual age. Adapted with permission. ${ }^{41}$ 

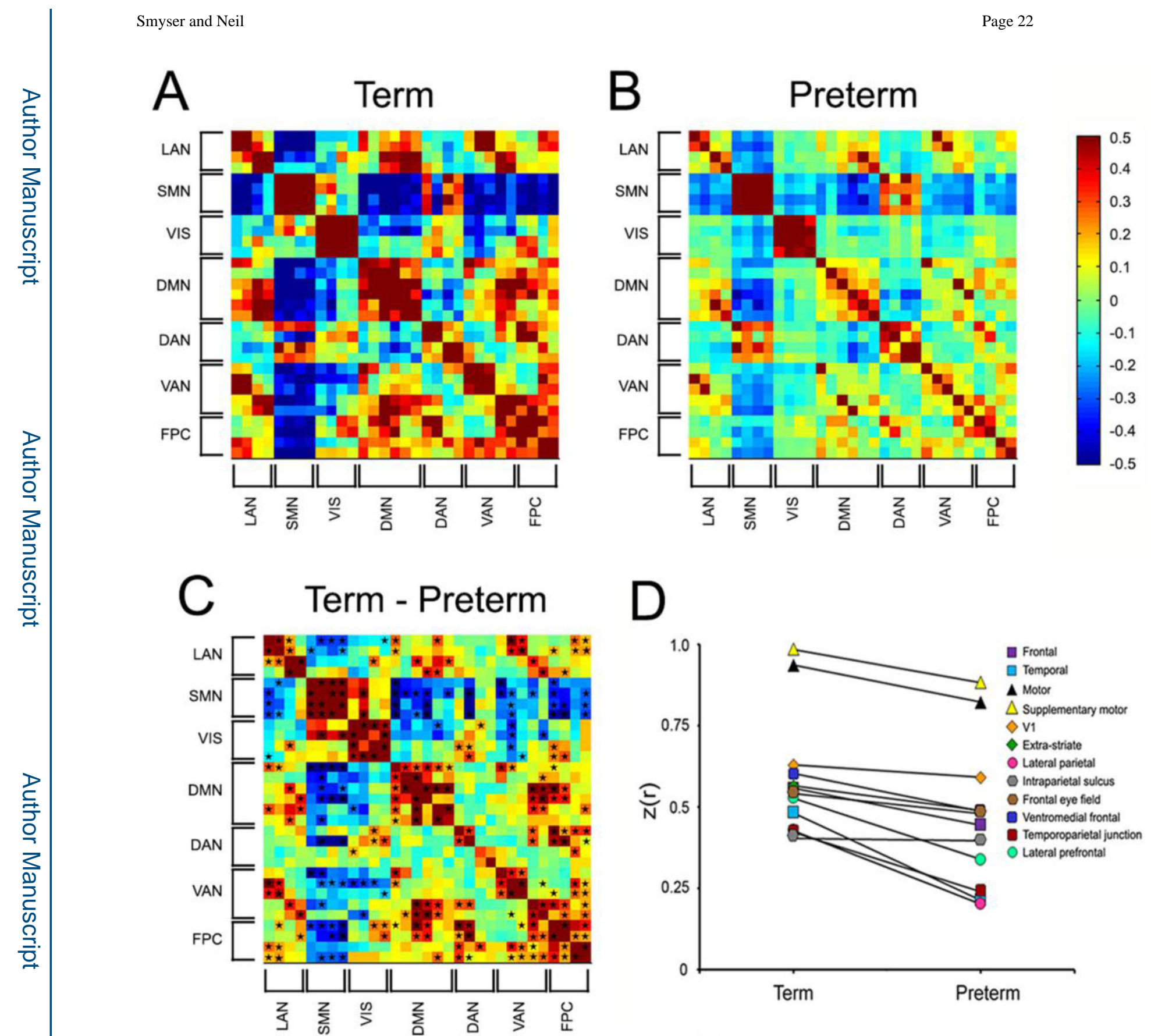

Figure 4. Term versus very preterm infant differences

Group mean covariance matrices representing multiple canonical RSNs for (A) term infants and (B) preterm infants at term equivalent postmenstrual age. (C) shows the difference (term minus preterm). Black stars in (C) denote cells with between group difference on two-tailed Mann-Whitney U-test ( $\mathrm{p}<0.05$; multiple comparisons uncorrected). (D) Group mean Fisher z-transformed correlation coefficients between homotopic ROIs pairs for term and very preterm infants. Note consistent term > preterm correlation values. Note also that areas that mature relatively early (e.g., motor and visual cortex) have higher correlation coefficients than those that mature more slowly. Adapted with permission. ${ }^{41}$ 

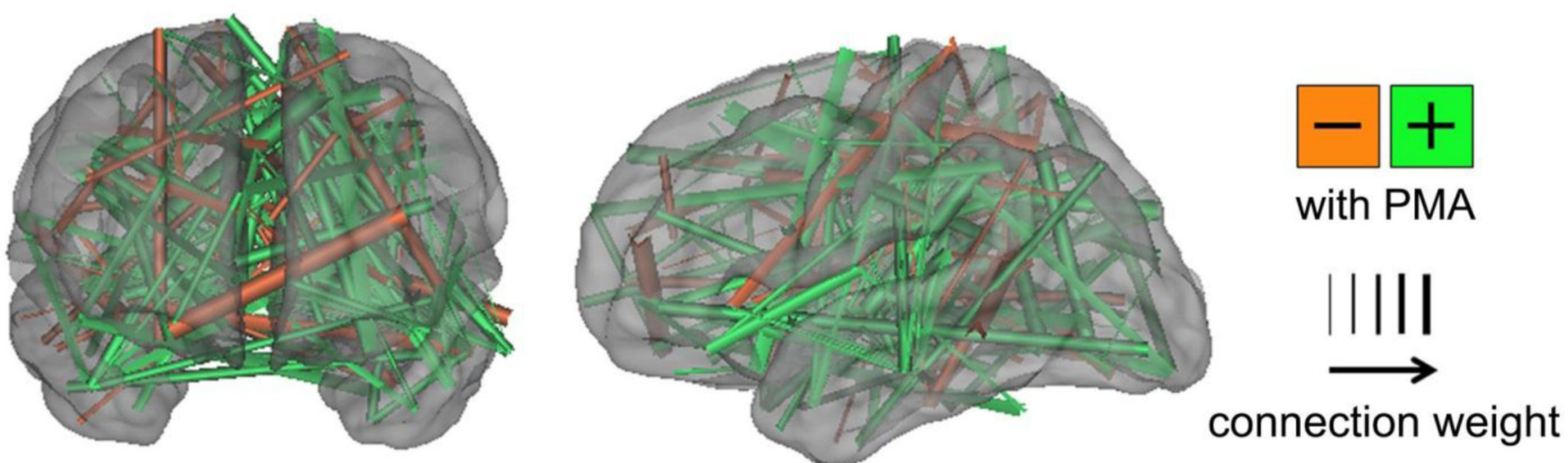

Figure 5. Support vector machine-multivariate pattern analysis demonstrating differences between term and very preterm infants

Functional connections important for differentiating term versus very preterm infants were determined using SVM. Connections stronger in term infants are shown in green; those stronger in very preterm infants are in orange. The thickness of each connection is weighted by the difference magnitude. Results were generated using 244 regions of interest located throughout the brain. Fifty infants scanned at comparable postmenstrual age with lowmotion fcMRI data were included in each group. Findings are displayed on surface rendering of population-specific atlas image. Note that the differences between group are not confined to any particular area or network. 